\title{
Experiential learning for children's dental anxiety: a cluster randomized trial
}

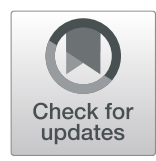

Minmin $\mathrm{Zhu}^{1 *+} \mathbb{D}$, Hongbing $\mathrm{Yu}^{1 \dagger}$, Bo Xie ${ }^{1 \dagger}$, Hongwen $\mathrm{Li}^{2}$, Qian $\mathrm{He}^{1}$, Huimin $\mathrm{Li}^{1}$, Jing Su${ }^{1}$ and Xueqi $\mathrm{Li}^{2^{*}}$

\begin{abstract}
Background: Dental anxiety (DA) has an impact on the quality of dental treatment and may have long-lasting implications for children. A recent study introducing experiential learning (EL) into children's oral health promotion resulted in better oral hygiene. The purpose of the study is to evaluate whether EL can reduce children's DA.

Methods: In September 2018, we recruited 988 children aged 7-8 years from 24 classes to participate in a clusterrandomized trial. Classes were randomly assigned to EL (in which children received a lively presentation on oral health and participated in a role play in a simulated dental clinic in the classroom) or the Tell-Show-Do (TSD) group (in which children received a conventional TSD behavior management). The primary outcome was the prevalence of high DA after the procedure of pit and fissure sealant (PFS), assessed by a modified Children's Fear Survey Schedule-Dental Subscale. Secondary outcomes were changes in blood pressures (BP) and pulse rates (PR) before and after the PFS procedure. The intervention effects were estimated by means of mixed effect models, which included covariates of gender and school (and baseline value for BP and PR only), and a random cluster effect.

Results: In 396 children of the EL group who received the PFS treatment, the prevalence of high DA (score $\geq 38$ ) was $18.5 \%$, compared with $24.3 \%$ in 391 children of the TSD group (OR $=0.65 ; 95 \%$ confidence interval, $0.46-0.93$; $P=0.019$ ). The increases in BP and PR after the PFS were also significantly less in the EL group.

Conclusion: School-based experiential learning intervention before a dental visit is feasible and effective in reducing children's dental anxiety during PFS.

Trial registration: The trial was registered in Chinese Clinical Trial Registry on 5 January 2020 (No.: ChiCTR200002 8878, retrospectively registered).
\end{abstract}

Keywords: Dental anxiety, Child dentistry, Experiential learning, Efficacy, Tell-show-do, Cluster randomized trial

\section{Background}

Dental anxiety (DA), abnormal fear or dread of visiting the dentist and unwarranted anxiety over dental procedures, has an impact on the quality of dental treatment and may have long-lasting implications for children [1]. Cross-sectional and cohort studies published from 2000 to 2014 have reported prevalence of children's DA that

\footnotetext{
*Correspondence: zhuminmin1982@163.com; 756296691@qq.com

${ }^{\dagger}$ Minmin Zhu, Hongbing Yu and Bo Xie contributed equally to this work.

'Shenzhen Nanshan Center for Chronic Disease Control, Shenzhen 518054,

China

${ }^{2}$ Shenzhen Nanshan Maternal and Child Health Care Hospital, Shenzhen 518054, China
}

ranged from 10 to $20 \%$ [2]. DA sometimes leads to a series of uncooperative or disruptive behaviors before or during dental procedures, termed dental behavior management problems (DBMP), that result in stressful and unpleasant experiences for both the child and the dentist [3]. In addition, studies have shown that DA has a consistent impact on pain throughout the entire dental treatment [4], and DA/DBMP are associated with children's dental caries [5-8], resulting in a vicious cycle [9].

DA varies from very mild to extreme levels, and interacts with urgency of treatment, therefore different approaches to anxiety reduction may be appropriate given

(c) The Author(s). 2020 Open Access This article is licensed under a Creative Commons Attribution 4.0 International License, which permits use, sharing, adaptation, distribution and reproduction in any medium or format, as long as you give appropriate credit to the original author(s) and the source, provide a link to the Creative Commons licence, and indicate if changes were made. The images or other third party material in this article are included in the article's Creative Commons licence, unless indicated otherwise in a credit line to the material. If material is not included in the article's Creative Commons licence and your intended use is not permitted by statutory regulation or exceeds the permitted use, you will need to obtain permission directly from the copyright holder. To view a copy of this licence, visit http://creativecommons.org/licenses/by/4.0/ The Creative Commons Public Domain Dedication waiver (http://creativecommons.org/publicdomain/zero/1.0/) applies to the data made available in this article, unless otherwise stated in a credit line to the data. 
the level of anxiety $[10,11]$. Although it is possible to employ pharmacological interventions to manage high level of anxiety, such as anesthesia or sedation [12], dentists generally use communicational, behavioral and psychological techniques to manage children's low or moderate level of DA and achieve a high quality of dental care. These include methods such as "Tell-Show-Do" (TSD), voice control, distraction, modelling, restraint, and cognitive restructuring [13, 14]. Of these methods, however, some need specialist training, some cause psychological traumas to children, and most are only initiated just before or during dental treatment. In recent years, the most used non-pharmacological method has been TSD, which has generally been acceptable for the doctors, children and parents [15-18]. Nevertheless, the TSD is less effective than modelling $[19,20]$.

Experiential learning (EL) is an innovative learning technique by which knowledge or skill is gained through the experience of participating in real or simulated practical activities [21]. EL is based on the theory that one can generalize an experience into a conceptualization through reflective observation and then proceed to take action. Active and personalized learning are characters of EL. EL has been used effectively in enhancing knowledge, improving attitude and modifying behaviors in health education [22$24]$, and was recently introduced into children's oral health promotion, resulting in better oral hygiene [25].

Lack of control and unpredictability of the dental experience may be the dominant cause of DA [11]. By letting children participate in simulated dental activities before real treatment, EL is expected to help children develop knowledge of dental health and be familiar with the dental procedures, thus reduce DA among children. In this paper, we developed a school-based EL intervention and evaluated whether the EL was effective in reducing DA in primary school children.

\section{Methods Study design}

This was a 2-arm cluster-randomized control trial comparing EL and TSD for their effectiveness in reducing DA in children. This study had the approved by the Ethics Committee of the Shenzhen Nanshan Maternal and Child Health Care Hospital. All parents of the children participated provided written informed consent. The trial was registered in Chinese Clinical Trial Registry (ChiCTR2000028878).

\section{Participants}

The participants were children aged 7-8 years, selected in September 2018 from the second grade of primary schools in the Nanshan District of the city of Shenzhen, China. At this age, children in Shenzhen routinely receive pit and fissure sealant (PFS) as a prophylaxis for dental caries in permanent molar teeth, which is noninvasive procedure.
Although PFS is harmless, children still show anxiety when facing the fissure sealant and its metal tip [26].

\section{Recruitment}

The eligibility criteria for second grade classes were: 1) located in Nanshan District, Shenzhen City; 2) had 40 to 50 children aged 7-8 years; 3 ) agreed to participate. In September 2018, we used a multi-stage random sampling method to recruit the participants. We first used a table of random digits to select six primary schools in Nanshan that had four or more classes met eligibility criteria, and then random selected four eligible classes in each of the six schools. All children in the 24 selected classes were invited to take part in the study, and the informed consent were sent to their parents (Fig. 1). Children who already had a dental visit or refused to participate were excluded.

\section{Randomization and interventions}

In this trial, the class was the unit of randomization. The sampled classes were randomly assigned into the EL or TSD groups in 1:1 ratio in school blocks with the use of a table of random digits (Fig. 1). Cluster randomization was necessary to avoid between-group contamination and it was feasibly conduct school-based intervention. After receiving the signed informed consent from the parents, the intervention was implemented on a class by class basis. Neither the dentists, nurses nor field interviewers who assessed the outcomes were aware of the randomization assignments of the classes, as the measurements were the same for both groups. Only the dental nurses who performed the "Tell and Show" procedures were aware the assignments.

At the beginning of intervention, children in the EL group received a lively 40 -min presentation on oral health given by dentists. The standardized oral health education conveyed information about dental caries and their causes, proper toothbrushing and flossing, and the pit and fissure sealant, by using slides, cartoon videos, and dental models. One month later, the children participated in an EL activity in a simulated dental clinic in the classroom. In the activity, the dentists demonstrated the common tools of dentistry (mouth mirror, dental probe, dental handpiece and dental ejector, etc.). Then the children were organized in 4-person-groups for a five-minute role play around a dental bed, with which the children playing a patient, a dentist, a nurse and a parent. While one group of children performed their role play, the other children were in another room watching cartoon videos that delivered oral health education. And another month after that, they visited the dental clinic to receive the PFS treatment.

Children in the TSD group received a conventional 5min TSD behavior management session at the time of their visit to the dental clinic for the PFS procedure. The TSD behavior management process used in this study contained three procedures: Tell, a dental nurse explained 


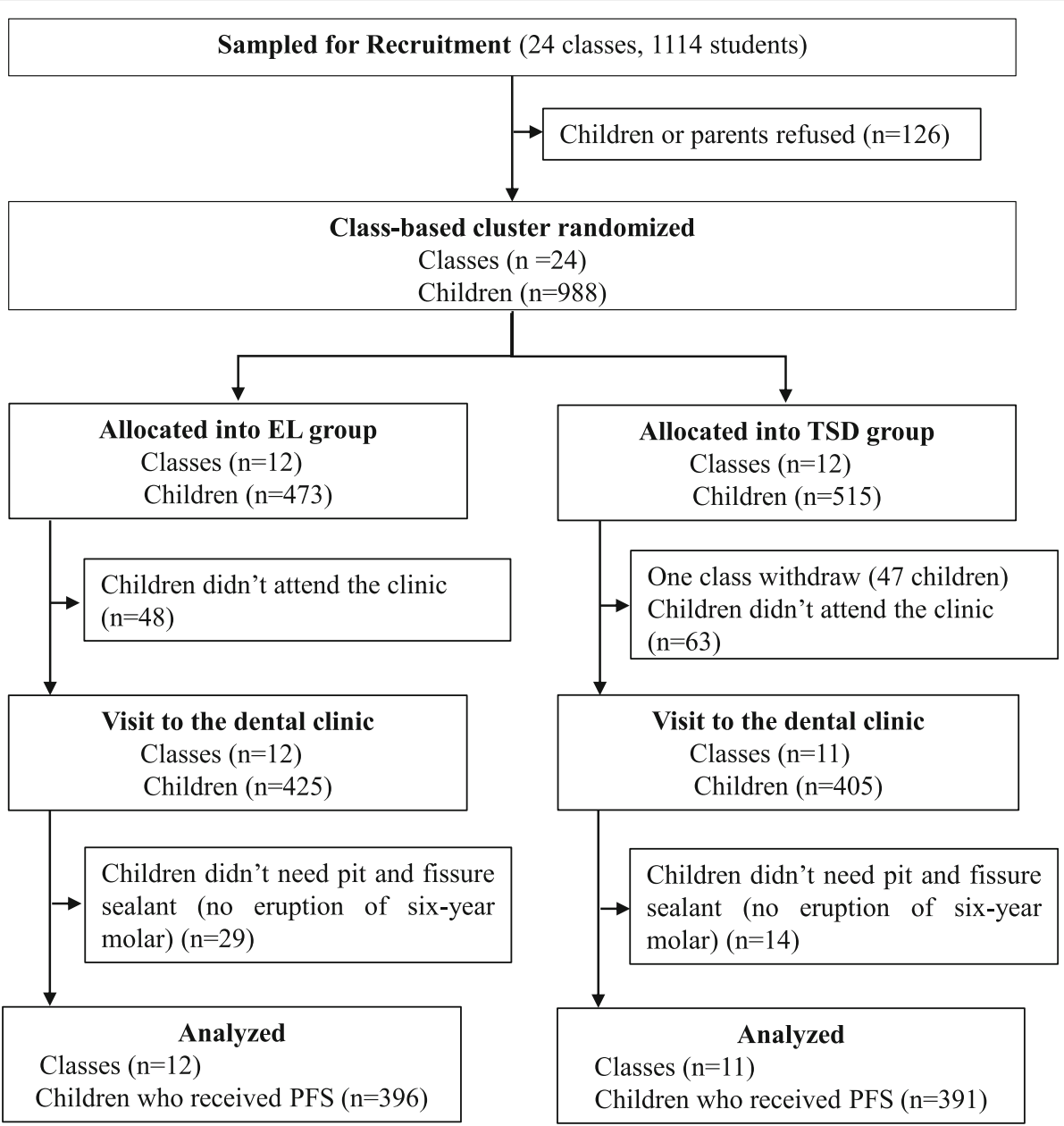

Fig. 1 Flow diagram of the trial of EL vs TSD for reducing children's dental anxiety. EL: Experiential learning, TSD: Tell-Show-Do

to the child what the dentist would do during the PFS treatment; Show, the dental nurse showed the equipment involved; Do, the dentist performed the PFS procedure.

\section{Trial measurement}

Another dental nurse (not the same one who delivered the TSD) performed the measurements of the children's blood pressures and pulse rates with an upper-arm electronic sphygmomanometer in the waiting room after a 15-min quiet sitting period before the PFS treatment, and then remeasured them again after the treatment.

The field interviewers administered the modified Children's Fear Survey Schedule-Dental Subscale (Modified CFSS-DS) [27] to the children after the PFS. The Modified CFSS-DS was translated into Chinese from the original English version and was combined with a facial image scale (FIS) [28]. It had a Cronbach's alpha of 0.85 and a test-retest reliability intraclass correlation coefficient of 0.73 [27].

\section{Outcomes}

The primary outcome was the prevalence of high DA, defined as a sum score of Modified CFSS-DS equal or above 38 [2]. The secondary outcomes were mean differences of change in systolic blood pressures (SBP), diastolic blood pressures (DBP) and pulse rates (PR) in the measurements taken before and after PFS.

\section{Statistical analysis}

With an enrollment of 12 class per trial group, 40 participants per class, a rate of cohort retention of $80 \%$, a rate of PFS of $90 \%$, and an estimated intraclass correlation coefficient $(0-0.01)$, the initial design yielded $80 \%$ power to detect a $10 \%$ difference in the prevalence of high DA between TSD and EL groups, with a two-sided alpha level of 0.05.

The intervention effects were estimated by means of mixed effect logistic regression for prevalence of high DA and linear mixed-effects model for continuous variations (DA score, SBP, DBP and PR), which included a random cluster effect of class. The primary predictor was group (EL versus TSD) and included covariates of gender and 
school (and baseline value for SBP, DBP and PR only), which were correlated with the dependent variable. All analyses were performed with the $\mathrm{R}$ project (Version 3.6.1 Patched for $\times 64$ Window system), and a $P$ value $<0.05$ was considered statistically significant.

\section{Results}

\section{Characters of participants}

A total of 24 classes from 6 schools were enrolled in the trial between Sept. 1st 2018 and Sept. 30th 2018, with a total initial enrollment of 988 children. The primary statistical analysis was based on the 396 participants in 12 EL classes and 391 participants in 11 TSD classes who completed the EL or TSD and the PFS treatment (Fig. 1). The two groups were similar in gender distribution and register residence (Table 1).

\section{Primary outcome}

The mean score of DA was 27.3 (Standard Deviation [SD]: 11.6) in the EL group and 29.2 (SD: 12.1) in the TSD group, with an adjusted mean difference of -2.5 (95\% confidence interval [CI]: $-4.9--0.2, P=0.042$ ). The prevalence of high DA (Modified CFSS-DS scores 238 ) was $18.5 \%$ in the EL group and $24.3 \%$ in the TSD group. The mixed effect logistic regression showed that the OR was 0.65 (95\% CI: 0.46-0.93; $P=0.019)$, after adjusting gender and school (Table 2).

\section{Secondary outcomes}

The mean SBP measured in the waiting room before the PFS was $108.7 \mathrm{mmHg}$ in the EL group and 107.8 in the TSD group. The mean change of SBP from before to after the PFS was -2.7 in the EL and 0.7 in the TSD group, with a $-2.6 \mathrm{mmHg}$ adjusted mean difference (95\% CI: -4.4 to $-0.9 \mathrm{mmHg} ; P=0.036$ ). The mean DBP after the procedure increased in both groups, but by $1.7 \mathrm{mmHg}$ in the EL group and $4.5 \mathrm{mmHg}$ in the TSD group, an adjusted mean difference of $-2.0 \mathrm{mmHg}$ (95\% CI: -4.4 to $0.3 \mathrm{mmHg} P=0.086$ ) (Table 2 ).

Table 1 Character of trial participants completing EL or TSD and PFS

\begin{tabular}{llll}
\hline Characters & $\begin{array}{l}\text { EL group } \\
(\boldsymbol{n}=396)\end{array}$ & $\begin{array}{l}\text { TSD group } \\
(\boldsymbol{n}=391)\end{array}$ & $\boldsymbol{P}$ value \\
\hline $\begin{array}{l}\text { Gender } \\
\text { Male }\end{array}$ & 221 & 226 & 0.623 \\
$\quad$ Female & 175 & 165 & \\
$\begin{array}{l}\text { Register Residence } \\
\quad \text { Shenzhen }\end{array}$ & 255 & 259 & 0.654 \\
$\quad$ Others & 124 & 116 &
\end{tabular}

EL Experiential learning, TSD Tell-Show-Do, PFS Pit and fissure sealant; ${ }^{a}$ The register residence was unknown for 17 and 16 children in the EL and TSD groups, respectively

${ }^{\$} P$ value was calculated with the chi-square test
The mean PR in the EL group increased by 0.2 Beats Per Minute (BPM), while in the TSD group it increased by $2.5 \mathrm{BPM}$, for an adjusted mean difference of -1.7 BPM (95\% CI: -3.4 to $-0.1 \mathrm{BPM} P=0.038$ ) (Table 2).

Detailed data of SBP, DBP and PR before and after the PFS according to the class cluster were illustrated (Fig. 2).

\section{Discussion}

To our knowledge, this is the first trial to assess the use of a school-based experiential learning intervention to reduce children's dental anxiety. On average, there were fewer children with high dental anxiety, as defined by a score of $\geq 38$ on the Modified CFSS-DS, in the EL group compared to the TSD group, with significantly lower increases in the SBP and PR after the PFS procedure.

There is evidence to suggest that classical conditioning plays a major role in the development of DA [1]. Children who have had a negative dental experience will have more DA [29], and can lead to DA in adulthood [30]. When enter an unfamiliar circumstance, the level of children's anxiety will increase. In the conventional TSD management, the children only listened and observed the process of treatment immediately before they were subjected to and might not have been emotionally ready for the treatment.

To reduce high levels of dental anxiety over the long term, the most effective treatment is graded exposure [31]. In contrast to TSD, in this study, the EL intervention firstly educated the children about the dental procedures, then showed them the dental tools, and finally invited them to role play in a simulated dental clinic a month before their dental visit. Also, children would share their felling after the role play, a "reflective observation" on their experiences. It allowed them to become familiar with the common dental tools and experience a simulated dental procedure, but not to face unpredictable anxiety-inducing stimuli, making them gradually feel in control and will improve their self-efficacy. Similar to the EL intervention, Radhakrishna et al. modified the TSD technique by adding a component of learning through playing [32], and achieved lower DA scores.

In our trial we chose a cut-off value of 38 on the CFSSDS to define high DA, which was also used by most studies in the systemic review by Cianettic et al. [2]. The reduction of high DA obtained in our study, although not achieving the designed 10 percentage-point difference, was similar to that obtained during moderately invasive treatment with other non-pharmacologic techniques such as using modelling [20] or audiovisual distraction [33].

The blood pressure and pulse rate, physiological indicators of anxiety during the dental procedure, would be expected to increase during the treatment and slowly descend after it concluded [34]. A study showed that 
Table 2 Primary and secondary outcomes

\begin{tabular}{|c|c|c|c|c|}
\hline Outcomes & EL group & TSD group & Intervention effect $^{\text {a }}$ & $\boldsymbol{P}$ value \\
\hline DA (score) & $27.3 \pm 11.6$ & $29.2 \pm 12.1$ & $-2.5(-4.9--0.2)$ & 0.042 \\
\hline High DA (\%) & 18.5 & 24.3 & $0.65(0.46-0.93)$ & 0.019 \\
\hline \multicolumn{5}{|l|}{$\mathrm{SBP}(\mathrm{mmHg})$} \\
\hline At the waiting room & $108.7 \pm 12.1$ & $107.8 \pm 12.7$ & & \\
\hline After the PFS & $106.1 \pm 13.0$ & $108.5 \pm 14.2$ & & \\
\hline Change & $-2.7 \pm 12.8$ & $0.7 \pm 14.2$ & $-2.6(-4.4--0.9)$ & 0.036 \\
\hline \multicolumn{5}{|l|}{$\mathrm{DBP}(\mathrm{mmHg})$} \\
\hline At the waiting room & $66.2 \pm 9.5$ & $65.5 \pm 10.0$ & & \\
\hline After the PFS & $68.0 \pm 12.1$ & $70.0 \pm 11.6$ & & \\
\hline Change & $1.7 \pm 12.3$ & $4.5 \pm 12.9$ & $-2.0(-4.4-0.3)$ & 0.086 \\
\hline \multicolumn{5}{|l|}{ PR (Beats per minute) } \\
\hline At the waiting room & $93.1 \pm 14.0$ & $92.0 \pm 13.5$ & & \\
\hline After the PFS & $93.3 \pm 13.9$ & $94.4 \pm 13.4$ & & \\
\hline Change & $0.2 \pm 14.0$ & $2.5 \pm 12.2$ & $-1.7(-3.4--0.1)$ & 0.038 \\
\hline
\end{tabular}

TSD controlled increase of blood pressures in patients during dental therapy [35]. In this trial, EL intervention was more effective than TSD, as the SBP and PR increased less after the PFS in the EL group than in TSD group, and the mean differences of changes between the two groups were statistically significant.

Within various DA nonpharmacologic management techniques, some seek to enable dental treatment to be performed, and some seek to rehabilitate the dental anxiety. Physical restraint, distraction (diverts one's attention away from auditory and/or visual unpleasant stimuli) [33], modeling (behavior guidance), and tellshow-do (reduces uncertainty) probably belong to the techniques of enabling treatment. While cognitive behavioral therapy (CBT), a combination of both cognitive restructuring and behavioral modification interventions, rehabilitates the dental anxiety. A systematic review reported that pediatric patients who received CBT, especial graded exposure, reduced their dental anxiety [31]. In this study, EL intervention helped the children be familiar with the dental procedures, enabling dental treatment to be performed. Meanwhile, through self-experience, reflection and graded exposure, EL restructured children's negative cognition to dental therapy, which might help rehabilitate the dental anxiety.

Due to several considerations, we chose children in the second year of primary school as the target group for the EL intervention. These children have a high incidence of dental caries, some of them will probably visit the dentists soon. Also, they have better understanding than children in kindergarten. As it is right before the planned dental prophylaxis of pit and fissure sealing for the first permanent molar, the intervention can be conveniently executed and evaluated.

In contrast to the clinic-based intervention, schoolbased EL intervention can be conveniently performed at any time before the dental visit, on a large scale. School-based EL is effect in reduction of children's DA during PFS, and different EL activities might need to be delivered in schools to cover other dental procedures than PFS. In Shenzhen, or other cities in China, the children receive health education presentations regularly at school. We believe that simply adding a special oral health education and short session of role playing in a simulated dental clinic in the class can have a significant effect in reducing DA in children.

The limitation of our study was that we adopted "Per Protocol analysis" but not the gold standard analysis method of "Intention to Treat", this was due to missing outcomes for those children who did not attend the clinic and who did not need PFS. Also, it is possible that the reductions in $\mathrm{DA}, \mathrm{BP}$ and $\mathrm{PR}$ varied depending upon which role the children played in the EL (i.e. dentist, nurse, parent or patient), but we were 


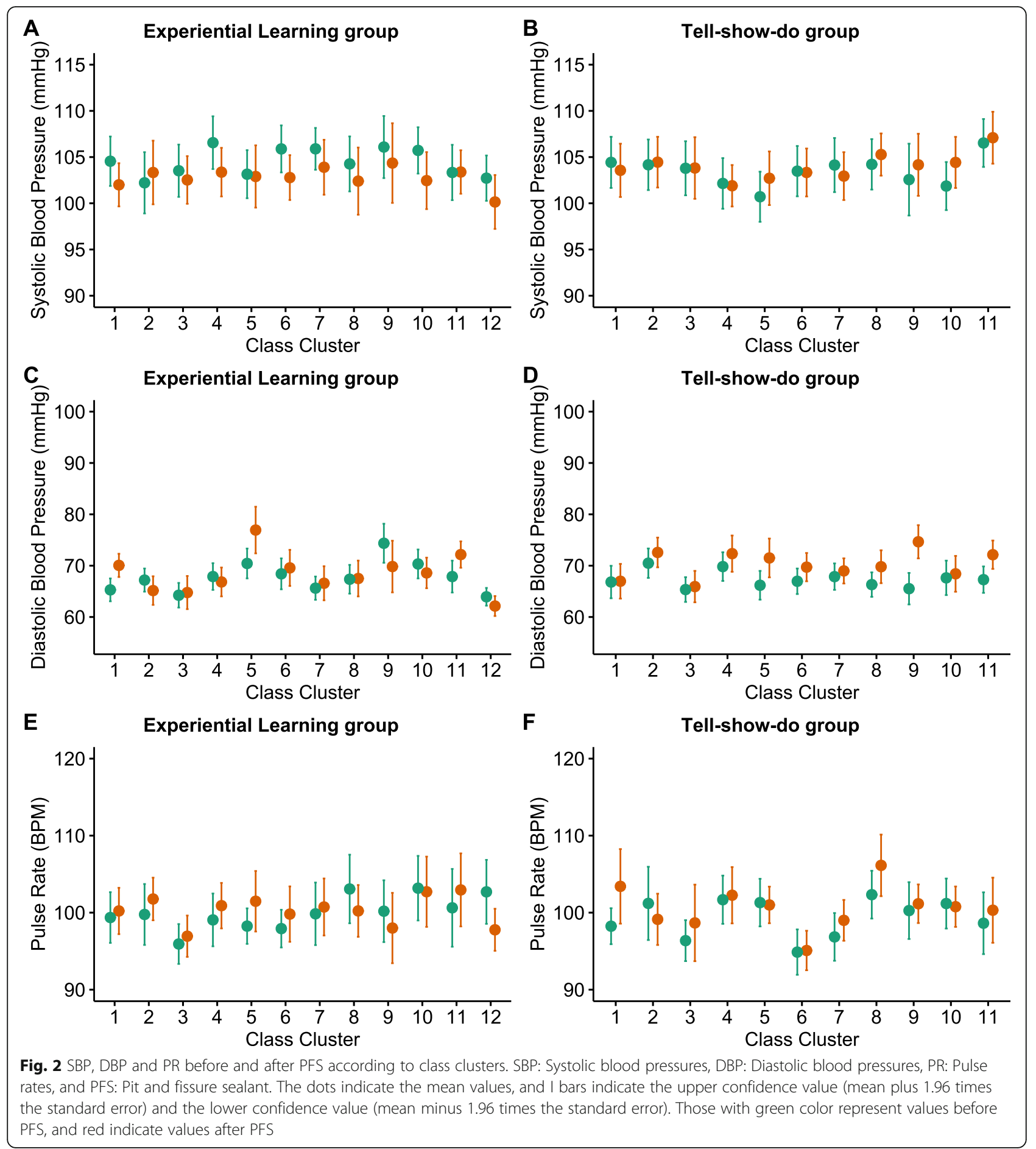

not able to evaluate this as we did not record roles for every child.

\section{Conclusion}

School-based experiential learning intervention before a dental visit is feasible and effective in reducing children's dental anxiety during the PFS. Not only will this make dental procedures easier and less traumatic for the dentists, nurses and children, but it could also reduce the potential for DA in adults.

\section{Abbreviations}

BPM: Beats per minute; BP: Blood pressures; CBT: Cognitive behavioral therapy; DA: Dental anxiety; DBMP: Dental behavior management problems; DBP: Diastolic blood pressures; EL: Experiential learning; Modified CFSSDS: Modified Children's Fear Survey Schedule-Dental Subscale; PFS: Pit and fissure sealant; PR: Pulse rates; SBP: Systolic blood pressures; SD: Standard deviation; TSD: Tell-Show-Do 


\section{Acknowledgements}

Many thanks to analysis suggestions and language editing form Howard E. Takiff in Shenzhen Nanshan Center for Chronic Disease Control and anyone who helped the implementation of the project.

\section{Authors' contributions}

MMZ contributed to conception, design, project coordination, data acquisition, analysis and interpretation, drafted and critically revised the manuscript; HBY, HWL contributed to conception, design, arranged and supervised the process of PFS, data interpretation, and critically revised the manuscript; BX contributed to design, guided measurement of the CFSS-DS, and critically revised the manuscript; QH, HML contributed to study design, data acquisition and analysis, and drafted the manuscript. JS contributed to design, intervention arrangement, data acquisition, and drafted the manuscript; XQL contributed to funding obtain, conception, design, project coordination, data acquisition and interpretation, and critically revised the manuscript. All authors gave their final approval and agree to be accountable for all aspects of the work.

\section{Funding}

This study was granted by Scientific and Technology Research and Development fund (No. JCYJ20170306155909623) from the Science and Technology Innovation Committee of Shenzhen City.

\section{Availability of data and materials}

The datasets used and/or analyzed during the current study are available from the corresponding author on reasonable request.

\section{Ethics approval and consent to participate}

This study had the approved by the Ethics Committee of the Shenzhen Nanshan Maternal and Child Health Care Hospital. All parents of the children participated provided written informed consent.

\section{Consent for publication}

Not applicable.

\section{Competing interests}

The authors declare that they have no competing interests.

Received: 28 February 2020 Accepted: 23 July 2020

Published online: 31 July 2020

\section{References}

1. Seligman LD, Hovey JD, Chacon K, Ollendick TH. Dental anxiety: an understudied problem in youth. Clin Psychol Rev. 2017:55:25-40.

2. Cianetti S, Lombardo G, Lupatelli E, Pagano S, Abraha I, Montedori A, et al. Dental fear/anxiety among children and adolescents. A systematic review. Eur J Paediatr Dent. 2017;18(2):121-30.

3. Klingberg G, Broberg AG. Dental fear/anxiety and dental behaviour management problems in children and adolescents: a review of prevalence and concomitant psychological factors. Int J Paediatr Dent. 2007;17(6):391406 .

4. Lin CS, Wu SY, Yi CA. Association between anxiety and pain in dental treatment: a systematic review and meta-analysis. J Dent Res. 2017;96(2): 153-62.

5. Stenebrand A, Hakeberg M, Helkimo AN, Koch G, Boman UW. Dental anxiety and oral health in 15-year-olds: a repeated cross-sectional study over 30 years. Community Dent Health. 2015;32(4):221-5.

6. Torriani DD, Ferro RL, Bonow ML, Santos IS, Matijasevich A, Barros AJ, et al. Dental caries is associated with dental fear in childhood: findings from a birth cohort study. Caries Res. 2014;48(4):263-70.

7. Zinke A, Hannig C, Berth H. Comparing oral health in patients with different levels of dental anxiety. Head Face Med. 2018;14(1):25.

8. Alsadat FA, El-Housseiny AA, Alamoudi NM, Elderwi DA, Ainosa AM, Dardeer FM. Dental fear in primary school children and its relation to dental caries. Niger J Clin Pract. 2018;21(11):1454-60.

9. Armfield JM. What goes around comes around: revisiting the hypothesized vicious cycle of dental fear and avoidance. Community Dent Oral Epidemiol. 2013;41(3):279-87
10. Newton T, Asimakopoulou K, Daly B, Scambler S, Scott S. The management of dental anxiety: time for a sense of proportion? Br Dent J. 2012;213(6): $271-4$.

11. Armfield $\mathrm{JM}$, Heaton LJ. Management of fear and anxiety in the dental clinic: a review. Aust Dent J. 2013;58(4):390-407.

12. Ashley PF, Chaudhary M, Lourenco-Matharu L. Sedation of children undergoing dental treatment. Cochrane Database Syst Rev. 2018;2018(12): CD003877.

13. Goettems ML, Zborowski EJ, Costa FD, Costa VP, Torriani DD. Nonpharmacologic intervention on the prevention of pain and anxiety during pediatric dental care: a systematic review. Acad Pediatr. 2017;17(2): $110-9$.

14. Anthonappa RP, Ashley PF, Bonetti DL, Lombardo G, Riley P. Nonpharmacological interventions for managing dental anxiety in children. Cochrane Database Syst Rev. 2017;2017(6):CD012676.

15. Strom K, Ronneberg A, Skaare AB, Espelid I, Willumsen T. Dentists' use of behavioural management techniques and their attitudes towards treating paediatric patients with dental anxiety. Eur Arch Paediatr Dent. 2015;16(4): 349-55.

16. Kantaputra PN, Chiewcharnvalijkit K, Wairatpanich K, Malikaew P, Aramrattana A. Children's attitudes toward behavior management techniques used by dentists. J Dent Child (Chic). 2007;74(1):4-9.

17. Peretz B, Kharouba J, Blumer S. Pattern of parental acceptance of management techniques used in pediatric dentistry. J Clin Pediatr Dent. 2013;38(1):27-30.

18. Boka V, Arapostathis K, Vretos N, Kotsanos N. Parental acceptance of behaviour-management techniques used in paediatric dentistry and its relation to parental dental anxiety and experience. Eur Arch Paediatr Dent. 2014;15(5):333-9.

19. Farhat-McHayleh $N$, Harfouche A, Souaid P. Techniques for managing behaviour in pediatric dentistry: comparative study of live modelling and tell-show-do based on children's heart rates during treatment. J Can Dent Assoc. 2009;75(4):283.

20. Karekar P, Bijle MN, Walimbe H. Effect of three behavior guidance techniques on anxiety indicators of children undergoing diagnosis and preventive dental care. J Clin Pediatr Dent. 2019:43(3):167-72.

21. Kolb DA. Experiential learning: experience as the source of learning and development. 2nd ed. USA: Pearson FT Press; 2014

22. Dyck RA, Kleinman NJ, Funk DR, Yeung RO, Senior P, Yardley JE. We can work (it) out together: type 1 diabetes boot camp for adult patients and providers improves exercise self-efficacy. Can J Diabetes. 2018;42(6):619-25.

23. Battjes-Fries MCE, Haveman-Nies A, Zeinstra GG, van Dongen EJl, Meester $H J$, van den Top-Pullen $\mathrm{R}$, et al. Effectiveness of taste lessons with and without additional experiential learning activities on children's willingness to taste vegetables. Appetite. 2017:109:201-8.

24. Matthews Jl, Zok AV, Quenneville EP, Dworatzek PD. Development and implementation of FRESH--a post-secondary nutrition education program incorporating population strategies, experiential learning and intersectoral partnerships. Can J Public Health. 2014;105(4):e306-11.

25. Angelopoulou MV, Kavvadia K, Taoufik K, Oulis CJ. Comparative clinical study testing the effectiveness of school based oral health education using experiential learning or traditional lecturing in 10 year-old children. BMC Oral Health. 2015;15:51.

26. Alnamankany A. Video modelling and dental anxiety in children. A randomised clinical trial. Eur J Paediatr Dent. 2019;20(3):242-6.

27. Lu JX, Yu DS, Luo W, Xiao XF, Zhao W. Development of Chinese version of children's fear survey schedule-dental subscale. Zhonghua Kou Qiang Yi Xue Za Zhi. 2011:46(4):218-21.

28. Buchanan $\mathrm{H}$, Niven N. Validation of a facial image scale to assess child dental anxiety. Int J Paediatr Dent. 2002;12(1):47-52.

29. Townend $E$, Dimigen G, Fung D. A clinical study of child dental anxiety. Behav Res Ther. 2000:38(1):31-46.

30. Oliveira MA, Vale MP, Bendo CB, Paiva SM, Serra-Negra JM. Influence of negative dental experiences in childhood on the development of dental fear in adulthood: a case-control study. J Oral Rehabil. 2017:44(6):434-41.

31. Gomes HS, Viana KA, Batista AC, Costa LR, Hosey MT, Newton T. Cognitive behaviour therapy for anxious paediatric dental patients: a systematic review. Int J Paediatr Dent. 2018:28:422-31.

32. Radhakrishna S, Srinivasan I, Setty JV, MK DR, Melwani A, Hegde KM Comparison of three behavior modification techniques for management of anxious children aged 4-8 years. J Dent Anesth Pain Med. 2019;19(1):29-36. 
33. Liu Y, Gu Z, Wang Y, Wu Q, Chen V, Xu X, et al. Effect of audiovisual distraction on the management of dental anxiety in children: a systematic review. Int J Paediatr Dent. 2019;29(1):14-21.

34. Brand HS. Cardiovascular responses in patients and dentists during dental treatment. Int Dent J. 1999:49(1):60-6.

35. Samra-Quintero PA, Bernardoni-Socorro C, Borjas AM, Fuenmayor NR, Estevez J, Arteaga-Vizcaino M. Changes in blood pressure in children undergoing psychological treatment before dental procedures. Acta Odontol Latinoam. 2006;19(1):9-12.

\section{Publisher's Note}

Springer Nature remains neutral with regard to jurisdictional claims in published maps and institutional affiliations.

Ready to submit your research? Choose BMC and benefit from:

- fast, convenient online submission

- thorough peer review by experienced researchers in your field

- rapid publication on acceptance

- support for research data, including large and complex data types

- gold Open Access which fosters wider collaboration and increased citations

- maximum visibility for your research: over $100 \mathrm{M}$ website views per year

At $\mathrm{BMC}$, research is always in progress.

Learn more biomedcentral.com/submissions 